\title{
Escravidão indígena no sertão da Capitania do Rio Grande do Norte
}

Indigenous slavery in the remote backlands of Rio Grande do Norte Captaincy

Helder Alexandre Medeiros de Macedo*

\section{Resumo}

Partindo de fontes de natureza civil, judicial e eclesiástica existentes em Natal, Acari e Caicó, o artigo propõe-se a discutir a existência de escravos índios no sertão da Capitania do Rio Grande e sua relação com as atividades econômicas nesse território, sobretudo a pecuária e a agricultura de subsistência. Toma como recorte espacial o território da Freguesia da Gloriosa Senhora Santa Ana do Seridó, cuja cartografia era formada por espaços das Capitanias do Rio Grande e da Paraíba.

Palavras-chave: escravidão indígena; Capitania do Rio Grande; sertão.

\section{Abstract}

Based on civil, judicial and ecclesiastical sources that exist in Natal, Acari, and Caicó, the article argues the existence of Indian slaves in the remote hinterland of Rio Grande do Norte Captaincy and their relation to the economic activities in this territory: livestock raising and sustainable agriculture. It examines in detail the region of the Parish of Gloriosa Senhora Santa Ana do Seridó, which included areas from the Captaincies of Rio Grande do Norte and Paraíba.

Keywords: indigenous slavery; Captaincy of Rio Grande; hinterland.

Desaparecimento. Essa palavra resume a sensação que nos fica quando adentramos pela história do Seridó, sertão do Rio Grande do Norte, gravada nas páginas da historiografia regional, sobretudo nos trechos que remetem aos índios. ${ }^{1}$ De maneira geral os nativos são alvo da atenção desses historiadores durante o período imediatamente anterior à chegada dos conquistadores luso-brasílicos e, com ênfase maior, durante as guerras de conquista destes últimos com vistas à ocupação do território por intermédio da pecuária. Efetivado o empreendimento da conquista após as guerras e levantadas fazendas com seus currais nas ribeiras - que seriam germes de povoações, freguesias e

\footnotetext{
* Mestre em História e Espaços, Pesquisador da Fapern - Centro Administrativo do Estado BR 101- Km 094 - Lagoa Nova. 59064-901 Natal - RN — Brasil. helder.ufrn@gmail.com.
} 
vilas denominadoras do espaço com o decurso do tempo - , parece que as populações indígenas não mais se faziam presentes: teriam sido exterminadas completamente durante as guerras, fugido para outras capitanias, retornado à vida errante ou mesmo se integrado à sociedade colonial. Em sendo verdadeira esta última possibilidade, a historiografia regional acima mencionada não parece ter tido interesse em relatar o quanto os índios participaram do cotidiano dos moradores da Ribeira do Seridó. É possível pensar, desse modo, numa marginalização historiográfica dos índios nas obras que descreveram a cultura, a história e o cotidiano do Seridó dos séculos XVIII e XIX. ${ }^{2}$ Em pesquisa a que procedemos nos documentos eclesiásticos, judiciais e civis inerentes à Freguesia de Santa Ana do Seridó interessou-nos buscar elementos que pudessem esclarecer uma dúvida: teria havido escravidão indígena na região em apreço após os conflitos das Guerras dos Bárbaros?

A inspeção que realizamos na documentação citada, com a finalidade de perceber como os índios presentes nesse território comportavam-se, nos ritos cristãos, na qualidade de fregueses, nos proporcionou apenas um lado da história. ${ }^{3}$ Mesmo comentando alguns dos casos que encontramos dentro das séries populacionais formadas a partir dos livros de assento, os resultados apresentados tiveram caráter genérico. Isso porque são os números, nesse caso, que nos permitem inferir determinados perfis dos fregueses de Santa Ana e, dentre eles, da população indígena que habitava no seu território. Sentimonos atraídos, porém, a conhecer mais do que apenas o que os algarismos nos mostram, mesmo quando olhamos para as pessoas por trás deles. Momento em que nos interrogamos acerca da presença de escravos índios nessas ribeiras, após as guerras de conquista do final do século XVII e início do século XVIII.

Para responder a essa indagação, é necessário reduzir a escala de observação nesse amplo território que é o sertão da Capitania do Rio Grande, centrando as nossas atenções na estratégia que a administração eclesiástica utilizou para gerenciar as áreas que iriam ser evangelizadas: a criação das freguesias. Deixamos de observar, assim, as estruturas territoriais e demográficas da Freguesia de Santa Ana, partindo para esquadrinhar as tramas e tensões das vidas de seus fregueses índios. O procedimento que estamos usando ampara-se na micro-história, tendência historiográfica que se baseia na redução da escala de observação, na análise microscópica e na prospecção e estudo intensivo das fontes sobre o objeto em questão. Não busca, contudo, isolar os casos dos índios citados acima ou de tomá-los como típicos da Freguesia de Santa Ana. Em outras palavras, interessa-nos observar o "exemplo" e não o 
"exemplar", ${ }^{4}$ além de relacionar o individual com o coletivo e perceber as transformações em macro-escala, isso porque concordamos com a perspectiva de que a pesquisa em escala microscópica envolve a necessidade de questionamentos sobre questões de ordem macroestrutural. Infiltrando-se pelas entrelinhas de inventários post-mortem, notas cartoriais, justificações de dívida, autos de contas e assentos paroquiais, observemos com minúcia a trajetória do casal de "tapuias" Anastácio e Domingas.

Tivemos conhecimento da existência desses dois índios durante a leitura dos inventários post-mortem da Comarca de Caicó, em que deparamos com o arrolamento e partilha dos bens deixados pelo defunto Crispim de Andrade Bulhões, processado na Povoação de Nossa Senhora do Bom Sucesso do Piancó em $1737 .{ }^{5} \mathrm{O}$ inventário é um instrumento jurídico prescrito nas Ordenações Filipinas ${ }^{6}$ e que era realizado quando da morte de uma pessoa que deixasse bens a partilhar entre filhos menores, sendo o processo feito por ordem do Juiz dos Órfãos. A análise dos inventários da Comarca de Caicó produzidos no século XVIII nos permite visualizar, de maneira geral, dois blocos em que se dividiam os processos: o arrolamento propriamente dito (contendo a descrição dos herdeiros e bens) e a partilha (onde esses mesmos bens eram partilhados dentre os herdeiros do[a] defunto[a]). Autos de contas de tutela e curatela, testamentos e justificações de dívida eram peças acessórias que, dependendo da situação em que se encontrava o inventariado por ocasião de sua morte, poderiam também compor o inventário - que se traduz, assim, como fonte de grande valia para o entendimento do passado colonial, já que proporciona uma informação recorrente - o arrolamento dos bens e a partilha entre os herdeiros - , desvelando questões da vida familiar e cotidiana. Trata-se de documento que expõe a público as fortunas individuais de homens e mulheres e, utilizando-se da comparação de Sheila Faria, é como que uma "fotografia" em que se observa determinado momento da vida material e imaterial de pessoas que não existem mais, senão conservadas nas memórias familiares ou nos arquivos.

Esses dois índios moravam no sítio Pedra Branca, onde serviam como escravos à família de Crispim de Andrade Bulhões e de Antonia Ferreira Batista, composta, no ano de realização do inventário do primeiro (1737), dos filhos José Ferreira Batista, de 24 anos; Antonio Ferreira Batista, de 22 anos; Maria de Andrade, de 18 anos, casada com o capitão José da Maia Rocha; Maria da Assunção, de 17 anos e Ângela, de 13 anos, além das órfãs Francisca e Luzia, de 12 e 6 anos, respectivamente. O monte maior dos bens deixados por Crispim de Andrade foi orçado em $367 \$ 600$, valor considerado 
alto se atentarmos para o fato de que o valor de uma cabeça de gado, avaliada durante a partilha, era de $1 \$ 500$. Com o monte maior, portanto, poderiam ser compradas, na época, cerca de 245 cabeças de gado vacum.

Não nos assustemos, todavia, com esses dados. As folhas estilhaçadas da descrição dos bens somente mencionam 205\$000 distribuídos em 50 cabeças de gado vacum (entre grandes e pequenos, machos e fêmeas), 16 bestas de toda sorte (entre grandes e pequenas) e poldros. Pouco mais de $150 \$ 000$ representavam os quatro escravos do sítio: os dois "tapuias" Anastácio e Domingas, já mencionados (avaliados, respectivamente, em 60\$000 e 40\$000) e os negros Custódio e Maria, ambos do Gentio da Guiné (que, na avaliação dos partidores, foram orçados em $32 \$ 000$ e $25 \$ 000$ ). Afora os semoventes e os escravos, o rol dos bens de Crispim de Andrade listou apenas duas canastras usadas (no valor de 1\$600) e outro objeto, cuja descrição é impossível de ser lida porque o suporte do inventário está esburacado, mas, que foi avaliado em $4 \$ 000$. E uma dívida passiva no valor de $32 \$ 000$, sendo devedora Ana de Oliveira.

A julgar pela descrição do inventário - sem contar que o processo, por se tratar do mais antigo da Comarca de Caicó, encontra-se bastante estragado e corroído -, que não arrolou bens de raiz, Crispim de Andrade deveria ser foreiro do real proprietário da terra, que, infelizmente, não foi mencionado no texto do processo. Assim sendo, deveria pagar ao dono do sítio, periodicamente (em geral, uma vez por ano), o valor por estar arrendando suas terras, que poderia ser liquidado através de uma quantia em dinheiro, bens ou serviços. Os “moradores”, geralmente, eram pessoas com baixa condição de vida, que, para sobreviver, dependiam de colonos que detinham posses territoriais.

Os documentos posteriores à partilha dos bens e que fazem parte do processo de inventário confirmam essa posição da família de Crispim de Andrade. Logo em 1738 a filha Maria da Assunção contraiu casamento com Luís Ferreira Fernandes, que, como ela, já tinha sido morador no sítio Pedra Branca, sendo filho de Miguel Dias Fernandes e de Simoa Gonçalves de Oliveira. Após o casamento foram morar na Povoação de Nossa Senhora do Bom Sucesso do Piancó, de onde o marido dirigiu petição ao juiz ordinário e de órfãos para que fosse concedida a herança de Maria da Assunção, já que "com ela está vivendo de suas portas adentro e a alimentando com os seus poucos bens". Três anos depois (1741) seria a vez de Ângelo José Guedes (filho de Filipe Guedes e Custódia Maria de Holanda Cavalcanti, residentes na Vila de Igaraçu), morador na Ribeira das Espinharas, requerer do juiz ordinário e 
de órfãos que lhe fossem concedidos os bens que cabiam por legítima a Ângela Ferreira, com quem se casara e estava "fazendo vida marital de suas portas adentro, tendo-a e mantendo-a de sua fazenda”. Em ambos os casos a justiça atendeu os pedidos, expedindo o formal de partilha das duas filhas de Crispim de Andrade e ordenando a entrega dos bens.

Os dois filhos mais velhos deste último, em 1743, também deixaram claro em suas petições direcionadas à justiça que passavam por dificuldades econômicas. Nesse ano, José Ferreira Batista e Antonio Ferreira Batista requereram a sua emancipação, para poderem desfrutar dos quase $30 \$ 000$ que tiveram de legítima paterna, estando residindo, à época, no sítio Mãe d'Água. José Ferreira, no requerimento ao juiz ordinário do Piancó, alegou ser "bastantemente pobre" e não ter com que sustentar-se e seu irmão, tal qual, mencionou ser "sumariamente pobre". Ambos os pedidos foram atendidos e o filho mais velho, José Ferreira, ainda voltaria à Povoação do Piancó em 1747 para relatar, na condição de tutor das irmãs Francisca e Luzia - em substituição ao seu cunhado José da Maia Rocha, que migrara para Pernambuco - o estado em que se encontravam os seus bens.

No caso de Crispim de Andrade, a mais provável que fosse vaqueiro do sítio Pedra Branca, considerando que a maior parte dos seus bens era de cabeças de gado. Atividade que exercia, provavelmente, junto com o trabalho compulsório dos dois negros da Guiné, Custódio e Maria, mais os dois "tapuias" já aludidos. Anastácio e Domingas são, dessa maneira, verdadeira preciosidade, pois confirmam uma assertiva comum na historiografia recente acerca do sertão da Capitania do Rio Grande: a da utilização de mão-de-obra indígena - ao lado de mestiços e brancos pobres - na faina do pastoreio. ${ }^{7}$ Ainda mais, neste caso, onde a mão-de-obra era compulsória, já que os dois tapuias encontravam-se dispostos, no rol de bens do finado Crispim de Andrade, no "título de escravos", junto com os dois negros da Guiné. Isso indica outra singularidade: a de que a escravidão indígena existiu, ao lado da escravidão negra, pelo menos nas primeiras décadas em que a Ribeira do Seridó foi povoada com brancos, a julgar pelos dados oferecidos pelo inventário de Crispim de Andrade.

Perguntamo-nos, no ensejo, quais seriam as condições em que Anastácio e Domingas tinham sido escravizados. Afinal de contas, a legislação indigenista colonial - oscilante, hipócrita e contraditória para Beatriz PerroneMoisés - , se fez conhecer através de três dispositivos legais que decretaram a liberdade dos nativos em 1570, em 1609 e em 1680, isso para não mencionarmos a de 1757, no contexto das reformas pombalinas. Vejamos um exemplo. 
A lei de 1570, conquanto apregoasse a liberdade dos índios, aceitava a escravidão, desde que fosse decorrente das "guerras justas" 1609, para fazer cessar as escravizações ilícitas, nova lei declarou livres todos os índios da América Portuguesa - instrumento que seria revogado parcialmente com uma lei em 1611, restaurando a escravidão dos nativos capturados em "guerra justa" confirmada por El-rei. Todo esse vai-e-vem era fruto, em parte, de pressões políticas exercidas, a todo tempo, pelos jesuítas e pelos colonos, em razão de que a Coroa hesitava na maneira como elaborava sua legislação,

ao tentar conciliar projetos incompatíveis, embora igualmente importantes para os seus interesses. Os gentios cuja conversão justificava a própria presença européia na América eram a mão-de-obra sem a qual não se podia cultivar a terra, defendê-la de ataques de inimigos tanto europeus quanto indígenas, enfim, sem a qual o projeto colonial era inviável. ${ }^{10}$

Em se tratando de Anastácio e Domingas, a proximidade cronológica do inventário de Crispim de Andrade (1737) com os últimos eventos da resistência indígena na Capitania do Rio Grande, datados da década de 1720, nos instiga a pensar que esses dois nativos teriam sido cativados durante as Guerras dos Bárbaros, considerada, desde a década de 1680, “justa”. Diante da complicação que os conflitos na Ribeira do Açu e em seus afluentes estavam tomando a partir de 1687, o governador-geral do Brasil, Matias da Cunha, convocou um Conselho de Estado em que todos os teólogos, ministros, oficiais maiores e mais sujeitos de grau votaram para que os conflitos do sertão do Rio Grande fossem considerados como guerra "justa, devia ser ofensiva, e os prisioneiros cativos”. Ao ser sabedor da preparação do paulista Domingos Jorge Velho rumo a Palmares, para combater os negros aquilombados, o mesmo governador pediu-lhe que atalhasse a viagem e se demorasse no Rio Grande, para combater os índios sublevados. Disse Matias da Cunha ao paulista, em carta: "Espero que não só terão todas as glórias de degolarem os bárbaros, mas a utilidade dos que aprisionarem, porque por a guerra ser justa resolvi em Conselho de Estado, que para isso se fez, que fossem cativos todos os bárbaros que nela se aprisionassem". ${ }^{11}$

Um primeiro indicativo dessa situação encontra-se na forma de nomear esses escravos como "tapuias", ou seja, o genérico colonial utilizado para dar nome aos índios que habitassem o sertão e que falassem a língua travada, por vezes, dependendo do seu comportamento frente às tentativas de cristianiza- 
ção, chamados de bárbaros. Nos inventários de colonos de São Paulo referentes ao século XVII, analisados por Muriel Nazzari, é constante a presença de índios constituindo o rol dos bens dos inventariados, nominados de "forros" ou "administrados". Até meados desse século os índios eram arrolados nos inventários como parte dos bens do defunto, porém, não lhes era atribuído um valor em dinheiro, em função da referida lei de 1609, que "proibia a captura dos índios e declarava que todos os índios eram livres, quer estivessem convertidos e civilizados quer fossem pagãos e selvagens, e não podiam ser obrigados a trabalhar para ninguém contra a sua vontade". Isso mudou, segundo a autora, a partir do terceiro quartel do século XVII, quando os índios inventariados, além de serem avaliados monetariamente, passaram a ser publicamente leiloados para o pagamento de dívidas. Evidência que nos leva a acreditar, junto com Muriel Nazzari, que a própria Coroa, pelas brechas deixadas na legislação e pela vista grossa que fazia a determinados atos, até certo ponto tolerava a escravidão indígena. ${ }^{12}$

Outro indicativo é o fato de que havia certo incentivo para a escravatura, em larga escala, dos indígenas aprisionados nas pelejas ditas “justas”. Segundo a Carta régia de 25 de outubro de 1707, do montante obtido com a venda dos escravos adquiridos nos combates se deveria pagar "a despesa feita na guerra, os impostos 'quintos' que tocam à Coroa 'e sobrando alguma coisa, se há de dar jóia ao governador e o mais repartido pelos cabos, oficiais e soldados"” (grifos nossos). ${ }^{13}$ Traço marcante dessa repartição é um inventário comentado por John Monteiro em seu estudo acerca da escravidão indígena em São Paulo. Trata-se do arrolamento de João Almeida Naves, de Parnaíba, feito em 1715, onde aparece, entre os seus bens, "uma tal de Ana de Pernambuco, tomada evidentemente na Guerra dos Bárbaros, 'a qual ainda que parda é escrava como tal custou 300 e tantas oitavas de ouro'”. ${ }^{14}$ Embora seja mencionada como "parda" - provavelmente, mestiça com ascendência autóctone -, o seu exemplo nos dá a medida de como os índios cativados nas guerras de despovoamento do sertão do Rio Grande foram parar em diversos pontos da América Portuguesa.

Foge à nossa compreensão, em virtude das poucas referências que o texto do inventário nos fornece - nem mesmo as idades desses "tapuias" as traças nos deixaram saber - a forma pela qual Crispim de Andrade os adquiriu: através de compra em alguma praça ou como reparte de guerra, se ventilarmos a hipótese de o defunto ter tomado parte, em vida, de algum dos terços que foram enviados pela Coroa para o combate aos bárbaros nas ribeiras do sertão. Um problema que nos avizinhou, nesse sentido, foi o fato de Crispim 
de Andrade, Anastácio e Domingas somente nos serem conhecidos através do processo de 1737. Cruzamos seus nomes em outras fontes manuscritas analisadas, mas, nada encontramos. Presumimos, pelos indícios deixados no inventário, que a família tenha se mudado, após a morte do pai, para algum lugar nas proximidades da Povoação do Piancó.

Entretanto, a Freguesia de Santa Ana conheceu outros índios que, dada a posição que ocuparam, também devem ter se ocupado dos afazeres da pecuária. É o caso de Agostinho, "índio forro" que era casado com a negra Paula, escrava de propriedade de João Garcia de Sá Barroso, que compareceram à Capela da Serra Negra, em 1804, para batizar a filha Inácia. ${ }^{15} \mathrm{O}$ fato de ser casado com uma escrava e de ter o apositivo "forro" no seu nome indica que Agostinho encontrava-se enredado pela teia das relações de trabalho no sertão, possivelmente trabalhando como vaqueiro da fazenda de João Garcia de Sá Barroso.

Caso curioso, também, é o de José Pereira de Souza, que prestou depoimento, junto com os pardos Luís Teixeira de Melo e Antonio José de Azevêdo, em uma justificação de dívida feita a propósito do inventário de Manuel Marques do Nascimento, em 1789. ${ }^{16} \mathrm{Na}$ assentada das testemunhas, o escrivão do juízo grafou, após o nome de José Pereira de Souza, "com casta da terra”, expressão aplicada, no século XVIII, para designar índios. Ele era, à época, septuagenário e casado, morando na Ribeira das Espinharas, onde vivia "de ser vaqueiro". Aqui, além da referência ao trabalho livre do índio José Pereira, o encontramos perante o aparelho judiciário colonial e jurando aos Santos Evangelhos ao dar seu testemunho sobre uma dívida - fato que, por si só, nos leva a inferir que a atividade de vaqueiro ou sua condição de ser "casta da terra" não lhe tirou a capacidade de agenciar sua própria vida, oferecendo seu conhecimento, junto com dois pardos certamente conhecidos, para a resolução de uma dívida em juízo. Segundo Maria Leônia Chaves de Resende, tanto os assentos de paróquia quanto os relatórios das visitações das Minas Gerais, sobretudo do século XVIII, apontam a expressão "casta da terra" como rótulo aplicado aos índios, assim como "carijós", "gentio da terra", "partes do gentio", "descendem do mato" e "tapuias dos sertões". ${ }^{17}$

Se Agostinho e José Pereira gozavam das benesses do trabalho livre - o que não quer dizer que não fossem dependentes dos senhores de terra das ribeiras onde moravam -, o mesmo não aconteceu com os escravos que lidavam com o gado ou no eito. Referimo-nos aos curibocas, vocábulo que, com diversas variações nos tempos coloniais, designava o mestiço cuja ascendência era, em parte, indígena. As variações no que tange ao significado desses 
vocábulos ("curiboca”, "caboclo", "mameluco" e "pardo", por exemplo), segundo Jocélio Teles dos Santos, configura-se como um resultado do sistema lingüístico escravocrata, que, dependendo da situação, "permitira rearranjos conceituais e indicava uma flexibilidade do uso de categorias no Brasil colônia"18 - de forma que o que era considerado "caboclo" para um colono poderia ser tido como "curiboca" para outro.

Stuart Schwartz, ao discutir as hostilidades, interações e miscigenação ocorridas entre negros e índios durante os tempos coloniais, assegura que os termos "tapanhunos" (em tupi, para designar os primeiros africanos chegados ao Novo Mundo) e "negros da terra" (que se referia aos cativos indígenas) foram sendo suplantados, gradativamente, por novas terminologias. Assim, cafuzos, curibocas e caborés foram categorias usadas pelos colonos para remeterem aos descendentes mestiços fruto do contato afro-índio, evidência de que "o regime colonial apresenta uma tendência à criação de novas categorias sociais e espaciais em que o nascimento, status hereditário, cor, religião e concepções morais contribuíram para a criação de categorias étnicas ou pseudoraciais com atributos definidos" ${ }^{19}$

Tomemos, como uso dessas categorias, o exemplo de uma descrição da capitania de São José do Piauí, datada de 1772, em que o ouvidor Antonio José de Morais Durão classificava os tipos sociais daquela capitania da seguinte maneira:

Vermelho se chama na terra a todo índio de qualquer nação que seja; mameluco ao filho de branco e índia; caful ao filho de preto e índia; mestiço ao que participa de branco, preto e índio; mulato ao filho de branco e preta; cabra ao filho de preto e mulata; curiboca ao filho de mestiço e índia; quando se não podem bem distinguir pelas suas muitas misturas se explicam pela palavra mestiço o que eu faço, compreendendo nela os cabras e curibocas. (grifos nossos) ${ }^{20}$

Pelas palavras do ouvidor, percebemos que, além de dar nome aos escravos filhos de mestiços com índias, o termo "curiboca" englobava toda sorte de cativos cujo complexo grau de miscigenação impedia, no contato imediato, a sua distinção. Câmara Cascudo, em análise do perfil da população do Rio Grande do Norte, considerou "curiboca" sinônimo de "caboclo", resultante da mistura entre negros e índios, enquanto "mameluco" apontaria o resultado do cruzamento entre brancos e nativos. Examinando os livros de notas da Comarca de Caicó, encontramos um caso curioso: a alforria dada por uma senhora, Maria da Conceição, a uma escravinha parda e "meio mameluca", filha de 
outra cativa que tinha em sua fazenda. A carta de alforria, datada de 1804, foi registrada no livro de notas da Vila Nova do Príncipe a pedido da própria escrava Mariana, alforriada, que tinha apenas dois anos de idade naquele ano - certamente, representada pela mãe ou por um procurador branco. Vale a pena transcrevermos o trecho inicial da carta de alforria concedida por dona Maria da Conceição, que evidencia a ascendência autóctone da escrava:

Digo eu abaixo asinada que entre os mais bens que possuõ hé assim bem huma Escrava meio mamaluquia por nome Mariana idade de dois Annos a qual hé filha de huma Escrava minha que por muito minha vontade lhe faço esmola fasendo menção no que me toca a qual a hei por forra livre, e ... que de hoje para sempre digo que de hoje para todo sempre fica sendo. ${ }^{21}$

Os mamelucos teriam sido "a maior porcentagem de vaqueiros", enquanto os caboclos ou curibocas teriam ficado conhecidos na figura do "pequeno plantador de roçaria". ${ }^{22}$ Opinião, todavia, superada pela historiografia recente, que aponta os mestiços com ascendência indígena, fosse com negros ou brancos, como trabalhadores, indistintamente, das lavouras e da pecuária. ${ }^{23}$

$\mathrm{Na}$ Freguesia de Santa Ana a primeira referência a escravos curibocas que encontramos está encartada no inventário procedido na Cidade do Natal em 1772 em relação aos bens do defunto Manuel Ferreira Borges. ${ }^{24}$ Este, que em vida fora casado com Juliana Vieira de Melo, morava com a família como arrendatário na propriedade de Antonio Garcia de Sá Barroso, como se depreende das dívidas do casal, onde constava a obrigação de $5 \$ 760$ pela "renda do sítio em que mora" ${ }^{25}$ No monte maior do casal, orçado em $470 \$ 490$, além de bens de ouro, cobre, cavalar, cabrum, ovelhum e móveis de casa figuravam sete cativos (três crioulos, uma crioula, uma mulata, uma cabra e uma preta do Gentio da Guiné). Entretanto, na relação dos dotes que o co-herdeiro José da Costa Lopes levara do defunto, na ocasião em que casou com Maria Borges (filha de Manuel Ferreira Borges), constava uma escrava curiboca chamada Florência. Escrava que certamente ajudava dona Maria na lida diária na Serra do Cuité, onde residia, pelo menos, até o ano de 1801, quando faleceu José da Costa. ${ }^{26}$

Em 1819, a partilha amigável dos bens deixados por dona Josefa de Araújo Pereira ( $\left.2^{a}\right)^{27}$ arrolou, entre os cativos, o escravo Manuel, curiboca, de 14 anos, avaliado por $120 \$ 000$. Dona Josefa, que era casada com o português José Ferreira dos Santos, residia no sítio Picos de Cima, Ribeira do Acauã. Mas era possuidora, também, de partes de terras nos sítios da Carnaúba e do 
Ermo, ambos de criar gados, situados nas plagas do rio Carnaúba, afluente do Acauã, além de duas glebas na Serra do Cuité, destinadas à plantação de lavouras de milho e de mandioca - que, juntas, valiam em dinheiro mais que o dobro dos três sítios de pastoreio. Provavelmente o curiboca Manuel e os demais escravos (uma crioula de 21 anos, prenha; uma cabra, de 13 anos e um crioulo de 12 anos) deveriam dedicar-se mais ao cultivo das roças, vez que o inventário apontou a presença de apenas quatro cabeças de gado vacum e três de cavalar nos Picos de Cima.

Em outra ribeira da Freguesia de Santa Ana, a do Sabugi, foi realizado, em 1791, o inventário dos bens deixados por João Álvares de Oliveira, que foi casado com dona Antonia Corrêa de Barros. ${ }^{28}$ Também aqui se repete a situação traçada no parágrafo anterior: o casal possuía propriedades territoriais de duas naturezas, uma destinada ao criatório (o sítio Olho d'Água, na Ribeira do Sabugi) e outra onde se plantavam lavouras, na Serra do Teixeira, avaliadas, respectivamente, em $700 \$ 000$ e 50\$000. Malgrado a supervalorização do Olho d'Água, somente habitavam nos seus campos quatro cabeças de gado vacum e sete de cavalar. A presença de aviamentos junto aos bens do casal roda de moer mandioca com seu cobre e veio de ferro; prensa; banco; forno; cochos - indica que o sítio na chã da serra era bastante utilizado para o cultivo de lavouras. A maioria, senão a totalidade, dos 21 cativos listados no inventário deveria trabalhar nas roças do Teixeira: mulatos, cabras, angolas, crioulos e um curiboca, José, nascido em 1789.

Histórias como essas que comentamos, sobretudo se reconstruídas por meio do cruzamento de fontes de naturezas diversas (notas cartoriais, registros de paróquia, inventários post-mortem, sesmarias, apenas para citar exemplos), nos ajudam a compreender alguns dos efeitos da ocidentalização nos trópicos, com ênfase no sertão da América Portuguesa. A imersão dessas personagens - e de outras, certamente, ainda encobertas pela poeira nos arquivos - no mundo colonial é uma evidência de que, como disse Serge Gruzinski, a ocidentalização não acarretou o total arrasamento das culturas autóctones. Porém, produziu mestiçagens - do ponto de vista biológico e cultural -, entendidas como "um esforço de recomposição de um universo desagregado e como um arranjo local dos novos quadros impostos pelos conquistadores". ${ }^{29} \mathrm{Na}$ prática, confirmando o que a historiografia já tinha apontado, assinalamos a presença de escravos índios ao lado dos escravos africanos e crioulos, provavelmente trabalhando nas lides do pastoreio ou em atividades agrícolas em alguns pontos da Freguesia de Santa Ana do Seridó, no sertão da Capitania do Rio Grande. 


\section{NOTAS}

${ }^{1}$ Estamos nos referindo, em especial, às obras de DANTAS, Manoel. Homens d'outrora. Rio de Janeiro: Irmãos Pongetti Ed., 1941 (Bibliotheca de Historia Norte-Riograndense, IV); AUGUSTO, José. Seridó. Rio de Janeiro: Borsoi, 1954; MONTEIRO, Eymard L'Eraistre. Caicó: subsidios para a historia completa do município. Recife: Escola Salesiana de Artes Gráficas, 1945; DANTAS, José Adelino. Homens e fatos do Seridó antigo. Garanhuns: O Monitor, 1962; LAMARTINE, Juvenal. Velhos costumes do meu sertão. Natal: Fundação José Augusto, 1965; LAMARTINE, Oswaldo. Sertões do Seridó. Brasília: Centro Gráfico do Senado Federal, 1980.

${ }^{2}$ Essa marginalização dos índios na historiografia norte-rio-grandense já havia sido notada por Fátima Martins Lopes, em seu estudo sobre a instalação das vilas do Diretório Pombalino no âmbito da Capitania do Rio Grande: LOPES, Fátima Martins. Em nome da liberdade: as vilas de índios do Rio Grande do Norte sob o Diretório Pombalino no século XVIII. Recife, 2005. 700p. Tese (Doutorado em História do Brasil) - Universidade Federal de Pernambuco. p.22-27. O raciocínio de onde partimos está baseado na discussão efetuada por MOREIRA, Vânia Maria Losada. Índios no Brasil: marginalização social e exclusão historiográfica. Diálogos latinoamericanos, Aarhus, Dinamarca, n.3, p.87-113, 2001.

${ }^{3}$ MACEDO, Helder Alexandre Medeiros de. Sobreviventes: um estudo demográfico sobre a presença indígena nas uniões e casamentos da freguesia colonial de Santa Ana do Seridó, Rio Grande do Norte. História Unisinos, São Leopoldo, v.8, n.9, p.189-219, 2004.

${ }^{4}$ LEVI, Giovanni. Sobre a micro-história. In: BURKE, Peter. A escrita da história: novas perspectivas. São Paulo: Ed. Unesp, 1992. p.136. GINZBURG, Carlo. O queijo e os vermes: o cotidiano e as idéias de um moleiro perseguido pela inquisição. São Paulo: Companhia das Letras, 1987.

${ }^{5}$ LABORDOC, Fundo da Comarca de Caicó, $1^{\circ}$ Cartório Judiciário, Inventários post-morten, Caixa 01 - 1737-1774, Inventário de Crispim de Andrade - 1737.

${ }^{6}$ CODIGO Philippino ou Ordenações e Leis do Reino de Portugal recopiladas por mandado d'El-Rey D. Philippe I [1603]. 14.ed. Brasília: Edições do Senado Federal, 2004 (fac-símile da 14.ed., de 1870), Livro Primeiro, Título LXXXVIII, 4.

${ }^{7}$ MONTEIRO, Denise Mattos. Introdução à História do Rio Grande do Norte. Natal: Ed. UFRN, 2000. p.79; MONTEIRO, Denise Mattos. Terra e trabalho em perspectiva histórica: um exemplo do sertão nordestino (Portalegre-RN). Caderno de História, Natal: UFRN, v.6, n.1, jan.-dez. 1999, p.14.

${ }^{8}$ DOMINGUES, Ângela. Os conceitos de guerra justa e resgate e os ameríndios do Norte do Brasil. In: SILVA, Maria Beatriz Nizza da (Org.) Brasil: colonização e escravidão. Rio de Janeiro: Nova Fronteira, 2000. p.27.

${ }^{9}$ MEDEIROS, Ricardo Pinto de. A redescoberta dos outros: povos indígenas do sertão nordestino no período colonial. Recife, 2000. 280p. Tese (Doutorado em História do Brasil) - Universidade Federal de Pernambuco. p.89. 
${ }^{10}$ PERRONE-MOISÉS, Beatriz. Índios livres e índios escravos: os princípios da legislação indigenista do período colonial (séculos XVI a XVIII). In: CUNHA, Manuela Carneiro da (Org.) História dos indios no Brasil. 2.ed. São Paulo: Companhia das Letras; Secretaria Municipal de Cultura; Fapesp, 1998. p.116.

${ }^{11}$ Citado por PUNTONI, Pedro. A Guerra dos Bárbaros: povos indígenas e a colonização do Sertão Nordeste do Brasil, 1650-1720. São Paulo, 1998. 200p. Tese (Doutorado em História Social) - Universidade de São Paulo. p.111.

${ }^{12}$ NAZZARI, Muriel. Da escravidão à liberdade: a transição de índio administrado para vassalo independente em São Paulo colonial. In: SILVA, Maria Beatriz Nizza da (Org.) Brasil: colonização e escravidão. Rio de Janeiro: Nova Fronteira, 2000. p.31-2.

${ }^{13}$ PERRONE-MOISÉS, Beatriz. Índios livres e índios escravos: os princípios da legislação indigenista do período colonial (séculos XVI a XVIII), cit., p.127.

${ }^{14}$ MONTEIRO, John Manuel. Negros da terra: índios e bandeirantes nas origens de São Paulo. São Paulo: Companhia das Letras, 1994. p.137.

${ }^{15}$ Freguesia da Gloriosa Senhora Santa Ana do Seridó, Livro de Batizados no 01, ficha 184.

${ }^{16}$ Laboratório de Documentação Histórica, Fundo da Comarca de Caicó, $1^{\circ}$ Cartório Judiciário, Inventários post-morten, Caixa 02 - 1775-1789, Justificação de dívida em inventário de Manuel Marques do Nascimento - 1789.

${ }^{17}$ RESENDE, Maria Leônia Chaves de. Brasis coloniales: o gentio da terra na Minas Gerais setecentista (1730-1800). In: Latin American Studies Association - LASA, 2001, Annals, Washington (DC), 2001. p.7; Id. Devassa da vida privada dos índios coloniais nas vilas de El Rei. Estudos ibero-americanos, Porto Alegre: PUCRS, v.30, n.2, p.49-66, dez. 2004. p.55.

${ }^{18}$ SANTOS, Josélio Teles dos. De pardos disfarçados a brancos pouco claros: classificações raciais no Brasil dos séculos XVIII-XIX. Afro-Ásia, n.32, p.115-137, 2005. p.118.

${ }^{19}$ SCHWARTZ, Stuart. Tapanhuns, negros da terra e curibocas: causas comuns e confrontos entre negros e indígenas. Afro-Ásia, n.29-30, p.13-40, 2003. p.15.

${ }^{20}$ DURÃO, Antonio José de Morais. Descrição da Capitania de São José do Piauí, citado por MOTT, Luiz R. B. Piauí colonial: população, economia e sociedade. Teresina: Secretaria de Cultura do Estado do Piauí, 1975. p.22-23.

${ }^{21}$ Comarca de Caicó, Livro de Notas no $04-1802-1805$, p.84.

${ }^{22}$ CASCUDO, Luís da Câmara. História do Rio Grande do Norte. 2.ed. Rio de Janeiro: Achiamé; Natal: Fundação José Augusto, 1984. p.44.

${ }^{23}$ Como exemplo, ver MOTT, Luiz R. B. Piauí colonial..., cit., p.125-142, onde se discute a relação entre os índios e a pecuária.

${ }^{24}$ Comarca de Acari, Inventários post-morten, Maço 01, Processo nº 01, Inventário de Manuel Ferreira Borges - 1772.

${ }^{25}$ Trata-se do sítio Acari, na Ribeira do Acauã, que foi demarcado oficialmente em 1769 (Instituto Histórico e Geográfico do Rio Grande do Norte, Documentos avulsos, Livro do 
Escrivão Freitas. Registro de hum auto de demarcação do Acari pertencente ao Cap. Anto Garcia de Sá Barroso e a Felipe de Moura, a requerimento dos mesmos, em 1769).

${ }^{26}$ Freguesia da Gloriosa Senhora Santa Ana do Seridó, Livro de Enterros no 01, p. 69v.

${ }^{27}$ Comarca de Acari, Inventários post-morten, Maço 01, Processo n²6, Partilhas amigáveis de Josefa de Araújo Pereira Júnior - 1819.

${ }^{28}$ Laboratório de Documentação Histórica, Fundo da Comarca de Caicó, 1 Cartório Judiciário, Inventários post-morten, Caixa 03 - 1790-1797, Inventário de João Álvares de Oliveira -1791 .

${ }^{29}$ GRUZINSKI, Serge. O Pensamento mestiço. São Paulo: Companhia das Letras, 2001. p.110.

Artigo recebido em abril de 2008. Aprovado em setembro de 2008. 